\title{
Vicarious learning of common and uncommon associations in children'
}

\author{
SEYMORE SIMON, RAYMOND DITRICHS AND NANCY JAMISON
}

NORTHERN ILLINOIS UNIVERSITY

\begin{abstract}
The vicarious acquisition of common and uncommon verbal associations was studied in 347 children. Results indicated that a disposition for uncommon responding could be learned vicariously and was dependent solely on the model's performance; instructions to the model, as well as the presence or absence of vicarious reinforcement, were insignificant variables. No systematic relationships were found between imitative behavior and scores derived from 3 children's personality scales.
\end{abstract}

\section{Problem}

A fundamental problem in the experimental study of originality is to devise procedures for increasing the production of uncommon responses. The procedures which have been employed include the presentation of uncommon stimulus situations (Osborn, 1957), the elicitation of different responses to the same stimulus situation (Maltzman, Simon, Raskin, \& Licht, 1960; Osborn, 1957), and directed instructions to Ss (Maltzman, Bogartz, \& Breger, 1958).

An alternative procedure for increasing originality may be to expose Ss to the uncommon behavior of other individuals. While a number of investigators have demonstrated that a wide range of behaviors can be learned vicariously (Bandura \& Walters, 1963), few studies have been concerned with the vicarious learning of associative behavior and none, to the best of our knowledge, have investigated the vicarious learning of original behavior. The purpose of the present experiment therefore was to study the vicarious acquisition of common and uncommon associative responses in children and to examine some of the variables which may be of importance in the acquisition of such behavior.

\section{Method}

The Ss were 3474 th, 5 th, and 6 th grade male and female students drawn from three elementary schools. A total of 17 or $18 \mathrm{Ss}$ each were randomly assigned to 18 experimental groups; three control groups containing 13 Ss each were also employed. Grade levels and schools were approximately equally represented in the 21 groups.

All Ss were tested in groups ranging from 3-6. Ss were initially asked to free associate to four stimulus words and to record their responses in a booklet provided. Immediately following the free association task, Ss were asked to give six uses to each of three items taken from Guilford's Unusual Uses Test (automobile tire, safety pin, button); 2 min. per item was allowed. Experimental Ss were then told that some weeks earlier a boy about their age was also asked to give associations to words and that a tape recording had been made of his responses. Ss were simply instructed to listen to the tape.

The experimental subgroups listened to one of 18 different tapes which had been prepared. All tapes were made by the same E and S. The three independent variables represented on these tapes were the instructions which the model received, the model's actual performance, and whether or not the model received verbal reinforce- ment for his associations. Three different subgroups of Ss heard the model receive instructions to give either uncommon or common associations ("...try to give as your answers words that you think very few/most boys and girls would give as their answers") or "neutral" instructions ("... say the first word that comes to mind"). Under the three conditions of instruction, either $100 \%$ uncommon, $100 \%$ common, or $50 \%$ uncommon and $50 \%$ common associations were actually given by the model. Three repetitions of 24 stimulus words were presented to the model during the vicarious phase and the model responded to each of the stimulus words with the same uncommon, common, or half uncommon and half common associations on each repetition. Further, for half the Ss the model received verbal reinforcement from E ("Good") $100 \%$ of the time and for the other half of the Ss the model received no verbal reinforcement for his associations. The design was a 3 (instructions to model) by 3 (model's performance) by 2 (reinforcement vs no reinforcement to model) factorial with independent groups of Ss in each of the cells.

In lieu of vicarious experience, control Ss were given a digit cancellation task for a period of time corresponding to the listening sessions of the experimental Ss. Three subgroups of control Ss were given uncommon, common, or neutral instructions immediately prior to the transfer phase of the experiment.

In transfer, both experimental and control Ss were asked to free associate to 16 stimulus words. Eight of these test words were selected randomly from those words presented to the model during the vicarious phase and eight of the words were stimuli never before presented to the Ss in the experimental session. Three additional unusual uses items (key, watch, eyeglasses) were also administered during this transfer phase. Finally, several weeks following the experimental sessions, three children's personality inventories were given to all Ss. These inventories comprised a locus of control scale, a social desireability scale, and an intellectual achievement scale.

Responses on the word association and unusual uses tasks were scored empirically according to previously established norms (Simon, Lotsof, \& Pease, 1963). Scoring details have been described elsewhere (Maltzman et al, 1960). The common (dominant associative responses) and uncommon (frequency of occurrence $=1$ ) associations given by the model were obtained from the same norms.

\section{Results}

Simple analyses of variance revealed that the three control groups did not differ significantly from each other on the criterion word association and unusual uses measures. The data for these groups was therefore combined in subsequent comparisons with the performances of the experimental groups.

A 3 by 3 by 2 analysis of variance on the pretest word association means for the experimental groups yielded no significant main effects or interactions. A 3 by 3 by 2 by 2 (new vs repeated stimulus words) repeated measurements analysis of variance on the criterion word association data revealed that the main effect for the model's responses $(F=31.39, \mathrm{df}=2 / 300$, $\mathrm{p}<.001)$, the interaction between the model's responses and words $(F=22.61, d f=2 / 300, p<.001)$, and the 4 th order interaction $(F=2.91, \mathrm{df}=4 / 300, \mathrm{p}<.05)$ were significant sources of variance. Since plots of the 4 th order interaction failed to reveal any systematic trends, no further analyses were conducted to determine the 
locus of this effect. The interaction between the model's responses and words was evaluated by conducting individual $\mathrm{t}$ tests between the three main effect means for repeated and new stimulus words separately. Results indicated that, for repeated stimulus words, significantly more uncommon associations were given by Ss listening to a model give $100 \%$ uncommon associations $(\mathrm{Xu})$ than by Ss listening to a model give either $100 \%$ common (Xc) or $50 \%$ common and $50 \%$ uncommon associations $(\mathrm{Xc}-\mathrm{u})(\mathrm{p}<.001$ in both instances). The latter two groups did not differ significantly from each other. Further analysis revealed that only $14 \%$ of the responses given to these repeated stimulus words by $\mathrm{Ss}$ in Group $\mathrm{Xu}$ were the same as the responses given by the model. The means for Groups $\mathrm{Xu}, \mathrm{Xc}$, and $\mathrm{Xc}-\mathrm{u}$ were $64.09,103.25$, and 101.94 respectively. When the stimulus words presented to Ss on the test list were different from the ones presented to the model, Group $\mathrm{Xu}$ gave significantly more uncommon associations than did Group Xc-u ( $\mathrm{p}<.05)$; other differences were not statistically reliable. For Groups $\mathrm{Xu}, \mathrm{Xc}$, and $\mathrm{Xc}-\mathrm{u}$ the means were 91.63, 97.40, and 100.65, respectively.

Dunnett tests (one-sided) were conducted to compare the significant main effect means for the model's responses with control group performance. Results indicated that for repeated stimulus words (control mean $=91.82$ ) Group $\mathrm{Xu}$ gave significantly more uncommon associations than did Group $\mathrm{C}(\mathrm{p}<.001)$ and that Group Xc was just short of giving significantly more common responses than Group C $(.10>p>.05)$; the difference between Groups $\mathrm{Xc}-\mathrm{u}$ and $\mathrm{C}$ was not statistically reliable. For new stimulus words (control mean= 99.26) none of the differences between the experimental and control group means were significant.

Analyses of covariance were conducted on the number of common and unique responses given by the experimental groups on the unusual uses criterion items. In these analyses, adjustments were made for pretest unusual uses performance and unique responses were subjected to a square root transformation $(\sqrt{\mathrm{X}+.5})$. Results indicated that the experimental groups did not differe significantly from each other on either of these measures. Likewise, Dunnett tests revealed that the experimental groups did not differ from the control group in the number of common responses given. Similar Dunnett tests on the number of unique responses, however, indicated that the experimental groups listening to a model give uncommon associations gave significantly more unique responses on the unusual uses test than did the control group $(p<.05)$; other comparisons were not reliable. The transformed means for Groups Xu, Xc, $\mathrm{Xc}-\mathrm{u}$ and $\mathrm{C}$ were $1.96,1.75,1.82$, and 1.68 , respectively.

Product-moment correlations were conducted between scores derived from each of the personality scales and difference scores computed between criterion and pretest word association and unusual uses performances. Results indicated that the relationships were non-systematic and that the number of significant coefficients did not exceed chance expectancy.

\section{Diseussion}

The results of this study indicate that children can learn to give uncommon word associations by listening to another child associate to words and that this disposition for uncommon responding will transfer to other tasks, e. g., unusual uses test. It is not immediately clear, however, why similar transfer effects were not obtained between Groups $\mathrm{Xu}$ and $\mathrm{C}$ when new word association stimuli were presented to Ss. If reliable, this failure may indicate that the extent of the transfer effects obtained under vicarious conditions cannot readily be predicted from those obtained under comparable direct associative training procedures (e.g., Maltzman et al, 1960)。

The present results also reveal that imitation was solely a function of the model's performance; instructions to the model, as well as the presence or absence of vicarious reinforcement, were not significantly related to imitative behavior. The latter results do not agree with those reported by Kanfer \& Martson (1963) who failed to find significant modeling effects in the absence of vicarious reinforcement. However, differences in subject population, the nature of the response class employed, and temporal differences in measuring the acquisition of vicarious learning, among other methodological inequalities, make it impossible to adequately compare the two experiments. Similar procedural differences preclude a comparison of the insignificant relationships obtained in the present study between vicarious learning and scores derived from the personality scales with the significant relationships recently reported by Marlowe et al (1964). Finally, the finding that instructions to the model did not facilitate common or uncommon responding is not surprising in view of the fact that, contrary to results obtained with adult populations of Ss (Jenkins, 1958; Maltzman et al, 1958), direct instructions to control Ss were equally ineffective in producing reliable changes in associative behavior.

\section{References}

Bandura, A., \& Walters, R. H. Social learning and personality development. New York: Holt, Rinehart, \& Winston, 1963.

Jenkins, J. J. Effects on word-association of the set to give popular responses. Psychol. Rep., 1958, 5, 94.

Kanfer, F. H., \& Marston, A. R. Human reinforcement: vicarious and direct. J. exp. Psychol., 1963, 65, 292-296.

Maltzman, I., Bogartz, W., \& Breger, L. A procedure for increasing word association originality and its transfer effects. J. exp. Psychol., 1958, 56, 392-398.

Maltzman, I., Simon, S., Raskin, D., \& Licht, L. Experimental studies in the training of originality. Psychol. Monogr., 1960, 74 , No. 6 (Whole No. 493).

Marlowe, D., Beecher, R. S., Cook, J. B., \& Doob, A. N. The approval motive, vicarious reinforcement and verbal conditioning. Percept. mot. Skills, 1964, 19, 523-530.

Osborn, A. F. Applied imagination. New York: Scribner's, 1957. Simon, S., Lotsof, E. J., \& Pease, H. E. Associative originality training in children. Paper presented at the Midwestern Psychological Association Meetings, May, 1963.

Note

1. This research was supported by funds from USPHS Grant MH 08917-01. We would like to express our appreciation to the staffs of the Huntley, DeKalb, and University Schools for their cooperation in this study. Drs. E. J. Lotsof and W. James kindly provided us with copies of the personality scales. 